\title{
Fe-Natural Zeolite as Highly Active Heterogeneous Catalyst in Decolorization of Reactive Blue 4
}

\author{
H. Hassan and B. H. Hameed
}

\begin{abstract}
Heterogeneous Fenton-like reaction using Fe-natural zeolite (Fe-NZ) was investigated for the decolorization of Reactive Blue 4(RB4). The effect of iron ions loading, $\mathrm{H}_{2} \mathrm{O}_{2}$ concentration and initial $\mathrm{pH}$ value were investigated. The maximum decolorization efficiency of $98.71 \%$ was achieved at $0.60 \mathrm{wt} \%$ of iron ions loading, $16 \mathrm{mM} \mathrm{H}_{2} \mathrm{O}_{2}$ concentration and at initial $\mathrm{pH}$ of 2.5. The high performance of Fe-NZ indicates that the heterogeneous Fenton-like could be efficiently employed for the treatment of wastewater containing azo dye.
\end{abstract}

Index Terms-Natural zeolite, reactive blue 4, heterogeneous fenton, decolorization.

\section{INTRODUCTION}

Textile industries has become a high priority environmental concern among other industries due to the intense color of the dyes that lead to serious water resource problem including loss of water purity, and obstruct the light penetration which reduce the photosynthetic activity of marine life [1]. Yearly, about $7 \times 10^{5}$ ton of dyes has been produced worldwide and $10-15 \%$ of them have reached the water bodies through the industrial pollutants [2]. Azo dyes are one of the important class of commercial organic colorants and create serious problems in textile wastewater due to their versatility, brilliant color shades, low cost and strong bind with dyed materials [3]. Azo dyes are carcinogenic, mutagenic, recalcitrant, non-biodegradable by aerobic treatment and become toxic to human and animals [4].

Advanced oxidation process (AOPs) based on the in-situ generation of strong and non-selective oxidant species including hydroxyl radical $(\cdot \mathrm{OH})$ become potential alternative technologies to degrade and mineralize organic pollutants to carbon dioxide $\left(\mathrm{CO}_{2}\right)$ and water $\left(\mathrm{H}_{2} \mathrm{O}\right)$ at mild pressure and temperature condition [5], [6]. The AOPs can be broadly classified into: Fenton, Photo-Fenton, $\mathrm{UV} / \mathrm{H}_{2} \mathrm{O}_{2}$, ozonation and natural sunlight [1], [7]. Among the AOPs, Fenton is the most effective and promising technique to generate $\cdot \mathrm{OH}$ radical due to its simple operation, low energy consumption, and use of environmental-friendly reagents $\left(\mathrm{Fe}^{2+}\right.$ and $\left.\mathrm{H}_{2} \mathrm{O}_{2}\right)$ [8]. The classical Fenton involves the reaction between $\mathrm{Fe}^{2+}$ or $\mathrm{Fe}^{3+}$ with the presence of $\mathrm{H}_{2} \mathrm{O}_{2}$ for the generation of $\cdot \mathrm{OH}$ radical that able to degrade various

Manuscript received August 25, 2019; revised January 5, 2020.

H. Hassan is with Faculty of Chemical Engineering, Universiti Teknologi MARA, Cawangan Pulau Pinang, Malaysia (e-mail: hamizura179@uitm.edu.my).

B. H. Hameed is with the Department of Chemical Engineering, School of Engineering, Qatar University, P.O. Box 2713, Doha, Qatar (e-mail: b.hammadi@qu.edu.qa). persistent organic pollutants including azo dyes [9]. However, the process has challenge for application in industries due to the formation of stable ferric complexes $\left(\mathrm{Fe}-\mathrm{OOH}^{2+}\right.$ Eq. (1)) which impede the catalytic reaction due to their slow decomposition to generate $\mathrm{Fe}^{2+}$ (Eq. (2)) [10].

$$
\begin{gathered}
\equiv \mathrm{Fe}^{3+}+\mathrm{H}_{2} \mathrm{O}_{2} \leftrightarrow \equiv \mathrm{Fe}-\mathrm{OOH}^{2+}+\mathrm{H}^{+}\left(\mathrm{k}=3.1 \times 10^{-3}\right) \\
\equiv \mathrm{Fe}-\mathrm{OOH}^{2+} \rightarrow \cdot \mathrm{OOH}+\equiv \mathrm{Fe}^{2+}\left(\mathrm{k}=2.7 \times 10^{-3}\right)
\end{gathered}
$$

Moreover, the application of homogeneous Fenton is limited by the requirement of large amount of $\mathrm{H}_{2} \mathrm{O}_{2}$ as well as low $\mathrm{pH}$ condition (3-5). Therefore, secondary treatments are required for catalyst separation and neutralization which resulted in large-amount of iron-containing sludge that are resistant for disposal [8], [11]. These weaknesses can be overcome by heterogeneous Fenton process where the active phase species such as iron were immobilized onto the catalyst support. By using this technique, the iron leaching could be reduced and the formation of iron hydroxide sludge is prohibited and the spent catalyst can be recovered from the effluent [12]. Different materials such as clay [13], activated carbon [14], synthetic zeolite [15] polymer [16], and mesoporous silica [17] has been applied as catalyst support in heterogeneous Fenton oxidation. Synthetic zeolite is widely used as supported material in heterogeneous Fenton process due to its distinct ion-exchange capability, large surface area, high adsorption capacity, and promising thermal stabilities [15], [18]. Aleksić et al. [15] reported that more than $80 \%$ of TOC removal and $100 \%$ color removal were achieved when synthetic zeolite was utilized as heterogeneous Fenton catalyst. However, the high cost of synthetic zeolite limits its application especially in developing countries.

Natural zeolite is a hydrated aluminosilicate minerals with some good physicochemical features such as molecular sieving, cation exchange, catalysis and sorption. Because of its valuable properties, they are commercially used as adsorbents to eliminate dyes [19] and heavy metals [20]. These studies concluded that natural zeolite has a great potential as an adsorbent in removing the organic pollutant. The use of natural zeolite as support for Fenton-like process appears more beneficial than synthetic zeolite due to their low cost, abundance and reduced chemical pollution during production [21]. This study aims to investigate the decolorization of Reactive Blue 4 (RB 4) by Fe-natural zeolite via heterogeneous Fenton-like reaction. The effect of major operating conditions such as iron ions loading, catalyst dosage, initial $\mathrm{pH}$ solution and $\mathrm{H}_{2} \mathrm{O}_{2}$ concentration were studied for optimization of decolorization of $\mathrm{RB} 4$ via heterogeneous Fenton-like reaction. 


\section{EXPERIMENTAL}

\section{A. Materials}

Natural zeolite (NZ) was obtained from the School of Civil Engineering, Universiti Sains Malaysia. The material was formed in the granular form and was crushed using mortar and sieved to produce particles sizes of $125 \mu \mathrm{m}$ in diameter. RB 4 was obtained from Sigma-Aldrich Malaysia. Ferrous sulfate supplied by Sigma-Aldrich was used as iron source of the catalyst. Other chemical used were sulfuric acid $(98 \%$ purity), $30 \mathrm{wt} \%$ hydrogen peroxide and sodium hydroxide (99\% purity). All chemicals were used without further purification.

\section{B. Preparation of Fe-Natural Zeolite}

Impregnation method was used to immobilize the iron onto the NZ. In this process, required amount of ferrous sulfate salt was dissolved in distilled water to make an aqueous solution followed by the addition of NZ. The resultant suspension was continuously stirred at $70{ }^{\circ} \mathrm{C}$ in water bath until all water was evaporated. The sample was further dried overnight at $105{ }^{\circ} \mathrm{C}$ and subsequently calcined at $500{ }^{\circ} \mathrm{C}$ in a muffle furnace for $4 \mathrm{hr}$. Finally, the catalyst was stored in a desiccator to prevent moisture absorption.

\section{Characterization of Fe-Natural Zeolite}

The porosity, shape, and roughness of the NZ and Fe-NZ were characterized by scanning electron microscopy (SEM). The analysis was carried out using a scanning electron microscope (Model Leo Supra 50VP Field Emission, UK). The elemental composition present in the catalyst was determined using Energy Dispersive X-ray (EDX) microanalysis system (Oxford INCA 400, Germany) connected to the SEM.

\section{Catalytic Activity Test}

Experiments were conducted in a $250 \mathrm{~mL}$-stoppered glasses (Erlenmeyer flask). The volume of reaction solution was $200 \mathrm{~mL}$. The RB4 solution was freshly prepared at room temperature by dissolving suitable amount of powder in distilled water. In a typical experiment, $200 \mathrm{~mL}$ of $50 \mathrm{mg} / \mathrm{L}^{-1}$ of reaction solution was fixed. The initial $\mathrm{pH}$ of the solution was adjusted by an addition of $1.0 \mathrm{M}$ sulfuric acid or $1.0 \mathrm{M}$ sodium hydroxide. Then, the catalyst was added into the solution and the reaction was initiated by introduction of predetermined amounts of $\mathrm{H}_{2} \mathrm{O}_{2}$ into the solution and this time was measured as time zero $(t=0)$. The flasks were then located in a thermostated water bath shaker under stirring speed of $130 \mathrm{rpm}$. At regular time intervals, small amount of solution was withdrawn by a syringe and the catalyst was filtered through $0.45 \mu \mathrm{m}$ membrane for analysis.

The concentration of RB4 was measured using using a double beam UV/Vis spectrophotometer (Shimadzu, model UV 1601, Japan) at $595 \mathrm{~nm}$ wavelength. To prevent any loss of content, the samples withdrawn at each time interval were returned into the conical flask. The effect of iron ions loading $(0.20-1.0 \mathrm{wt} \%)$, catalyst dosage $(1.0-5.0 \mathrm{~g} / \mathrm{L}-1)$, initial $\mathrm{pH}$ value $(2.0-5.0)$, initial $\mathrm{H} 2 \mathrm{O} 2$ concentration $(4-20 \mathrm{mM})$ on the decolorization of RB4 were evaluated. The decolorization efficiency of RB4 was calculated according to Eq. (3):

$$
\text { Decolorization efficiency }(\%)=\frac{C_{0}-C_{t}}{C_{0}} \times 100 \%
$$

where $C O$ is the concentration of RB4 before the heterogeneous Fenton reaction and $C \mathrm{t}$ is the concentration of RB4 at the time of withdraw.

\section{RESULTS AND DiSCUSSION}

\section{A. Catalyst Characterization}

The surface of the NZ and $0.60 \mathrm{wt} . \% \mathrm{Fe}-\mathrm{NZ}$ particles were shown in Fig. 1(a)-(b). The image of NZ shows the heterogeneity of the particle size. Most of the particles had a rough surface except a few, which showed a smooth surface. In addition, the natural zeolite has well shaped needles, which represents a well crystallized mordenite. However, after impregnation process, the modified NZ exhibited poorly shaped needles and the surfaces become more porous.

The chemical composition of pristine NZ and $0.60 \mathrm{wt} \%$ of Fe-NZ are shown in Table 1. The EDX analysis showed that the oxide and iron content in Fe-NZ were increased by $0.7 \%$ after impregnation process due to transformation of iron containing complexes to iron oxide or hydroxide particles after calcinations. Slight variations between the determined and calculated iron content of the Fe-NZ due to the high hydration degree of solid at the initial stages of the catalyst preparation [22].

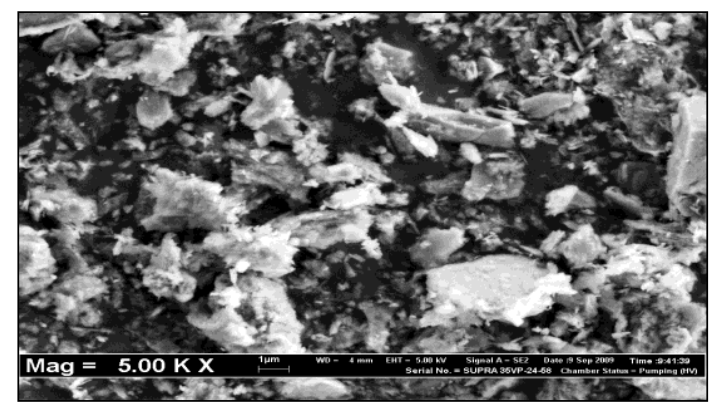

(a)

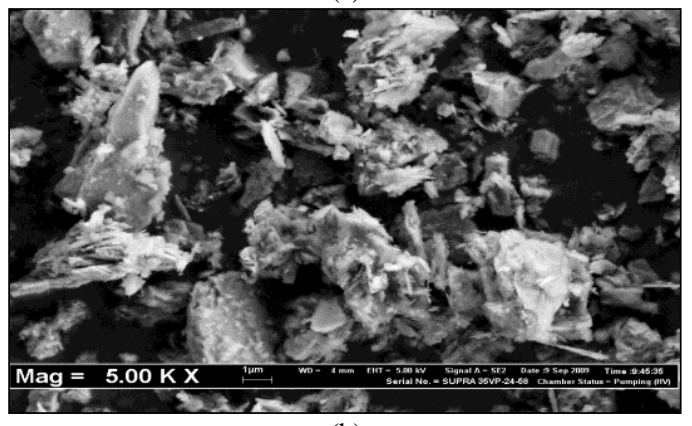

(b)

Fig. 1. SEM images of (a) NZ and (b) $0.60 \mathrm{wt} \%$ of Fe-NZ (Magnification: 5 $\mathrm{kx})$.

TABLE I: CHEMICAL COMPOSITION OF NZ AND 0.60 WT\% FE-NZ DETERMINED BY EDX

\begin{tabular}{ccc}
\hline \multirow{2}{*}{ Element } & \multicolumn{2}{c}{ Concentration (wt \%) } \\
& $\mathrm{NZ}$ & $\mathrm{Fe}-\mathrm{NZ}$ \\
\hline $\mathrm{Fe}$ & 6.62 & 7.32 \\
$\mathrm{Si}$ & 43.13 & 40.87 \\
$\mathrm{Al}$ & 9.87 & 9.69 \\
$\mathrm{O}$ & 40.38 & 42.12 \\
\hline
\end{tabular}

\section{B. Role of Different Mechanisms}

In order to elucidate the influence of different mechanism 
participating in the decolorization of RB4, several experiments were undertaken in presence of (i) $\mathrm{H}_{2} \mathrm{O}_{2}$ only (ii) raw NZ (adsorption on NZ) (iii) Fe-NZ (adsorption on Fe-NZ) (iv) $\mathrm{NZ}+\mathrm{H}_{2} \mathrm{O}_{2}$ only (v) $\mathrm{Fe}^{2+}+\mathrm{H}_{2} \mathrm{O}_{2}$ (homogeneous Fenton) (vi) $\mathrm{Fe}-\mathrm{NZ}+\mathrm{H}_{2} \mathrm{O}_{2}$ (Heterogeneous Fenton). From Fig. 2, less than $10 \%$ of decolorization of RB4 was achieved when $\mathrm{H}_{2} \mathrm{O}_{2}$ was used alone without NZ or Fe-NZ because RB4 was poorly oxidized due to low oxidation potential of $\mathrm{H}_{2} \mathrm{O}_{2}\left(\mathrm{E}^{0}=\right.$ $1.78 \mathrm{~V})$ as compared to hydroxyl $\left(\mathrm{E}^{0}=2.80 \mathrm{~V}\right)$ radicals [6]. In addition, the catalytic contributory role of $\mathrm{NZ}$ support and Fe-NZ catalyst were also verified in heterogeneous Fenton reaction. The result revealed that only $10.36 \%$ and $10.43 \%$ decolorization of RB4 were achieved when NZ and Fe-NZ were used alone, respectively without the presence of $\mathrm{H}_{2} \mathrm{O}_{2}$. Thus, it can be concluded that the adsorption of RB4 onto the $\mathrm{NZ}$ and Fe-NZ does not contribute significantly to the catalytic activity. In the presence of $\mathrm{NZ}$ and $\mathrm{H}_{2} \mathrm{O}_{2}$, slightly lower decolorization of RB4 was achieved due to inactive of $\mathrm{NZ}$ towards activation of $\mathrm{H}_{2} \mathrm{O}_{2}$ to generate ${ }^{\circ} \mathrm{OH}$ radical.

The contribution of homogeneous Fenton reaction was verified based on the amount of leached iron $\left(2.89 \mathrm{mg} \mathrm{L}^{-1}\right)$ after the third cycle of oxidation under optimum reaction condition. The decolorization efficiency of RB4 was increased drastically under homogeneous Fenton reaction. However, the decolorization efficiency of RB4 by leached iron was lower as compared to heterogeneous Fenton reaction. Almost 100\% decolorization efficiency of RB4 was achieved when heterogeneous Fenton $\left(\mathrm{Fe}-\mathrm{NZ}+\mathrm{H}_{2} \mathrm{O}_{2}\right)$ was applied, suggesting the synergistic effect resulted from between immobilized iron species and NZ support which have distinct adsorption properties [23]. Hence, it can be concluded the prominent role in decolorizatiom of RB4 was played by heterogeneous Fenton reaction where the iron species available on the surface of the catalyst or in the interlayer of catalyst could react with $\mathrm{H}_{2} \mathrm{O}_{2}$.

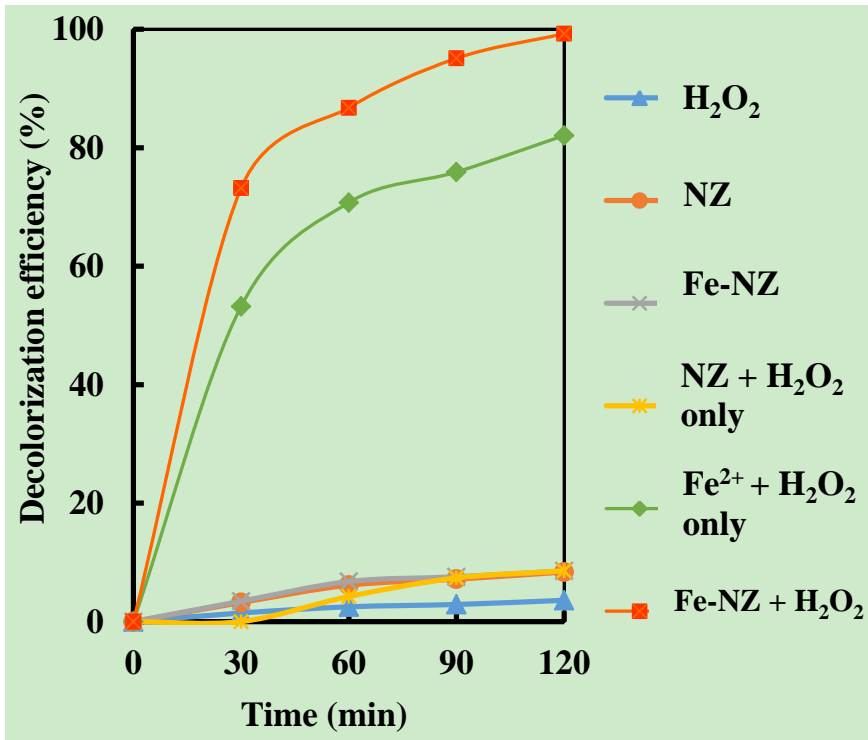

Fig. 2. Contributions of different mechanism on catalytic activity of Fe-NZ. Reaction conditions: $\mathrm{pH}=2.5$, catalyst dosage $=2.50 \mathrm{~g} / \mathrm{L},\left[\mathrm{H}_{2} \mathrm{O}_{2}\right]=16 \mathrm{mM}$, $[\mathrm{RB}]_{\mathrm{o}}=50 \mathrm{mg} \mathrm{L}^{-1}$, temperature $=30^{\circ} \mathrm{C}$.

\section{Effect of Iron Ions Loading}

In heterogeneous Fenton-like reaction, the iron species provide the active site for $\mathrm{H}_{2} \mathrm{O}_{2}$ decomposition and decolorization of dye. The influence of iron ions loading on catalytic activity was studied by varying the iron ions loading from 0.20 to $1.0 \mathrm{wt} \%$ and the result was shown in Fig. 3. Based on the result, the decolorization efficiency increased efficiently up to $0.60 \mathrm{wt} \%$ iron ions with the maximum decolorization of $93.84 \%$ in $120 \mathrm{~min}$. The maximum decolorization at $0.60 \mathrm{wt} \%$ could be due to increase of catalytic active site available for the decomposition of $\mathrm{H} 2 \mathrm{O} 2$ into $\bullet \mathrm{OH}$ [22]. Interestingly, no induction periods are observed and high initial decolorization rate were observed, suggesting Fe-NZ has enough quantity of active sites $\left(\mathrm{Fe}^{2+}\right)$ for faster production of highly reactive $\bullet \mathrm{OH}$ and heterogeneous Fenton reaction react as a main contributor in catalytic activity [24]. Induction period can be defined as a period of time needed for surface activation of metal species (decrease to lower oxidation state) or dissolve of adequate metal for initiation of homogeneous solution [3]. However, the decolorization decreased with further increased in iron ions loading, suggesting the inhibition effect induce by excess of iron ions loading on the $\bullet \mathrm{OH}$ as shown in Eq. (4).

$$
\equiv \mathrm{Fe}^{2+}+\mathrm{HO}^{\bullet} \rightarrow \mathrm{Fe}^{3+}+\mathrm{OH}^{-}
$$

In addition, when the iron ions loading is in excess compared to $\mathrm{H}_{2} \mathrm{O}_{2}$, the superoxide radical anion $\left(\mathrm{O}_{2}^{\bullet-}\right)$ could be produced in the presence of $\mathrm{O}_{2}$ as in Eq. (5). This radical could be further react with iron ions species as shown in Eq. (6).

$$
\begin{array}{r}
\equiv \mathrm{Fe}^{2+}+\mathrm{O}_{2} \rightarrow \equiv \mathrm{Fe}^{3+}+\mathrm{O}_{2}{ }^{\circ} \\
\equiv \mathrm{Fe}^{2+}+\mathrm{O}_{2}{ }^{+}+2 \mathrm{H}^{+} \rightarrow \equiv \mathrm{Fe}^{3+} \mathrm{H}_{2} \mathrm{O}_{2}
\end{array}
$$

All these reaction mechanisms could deaccelerate decolorization of dye [25].

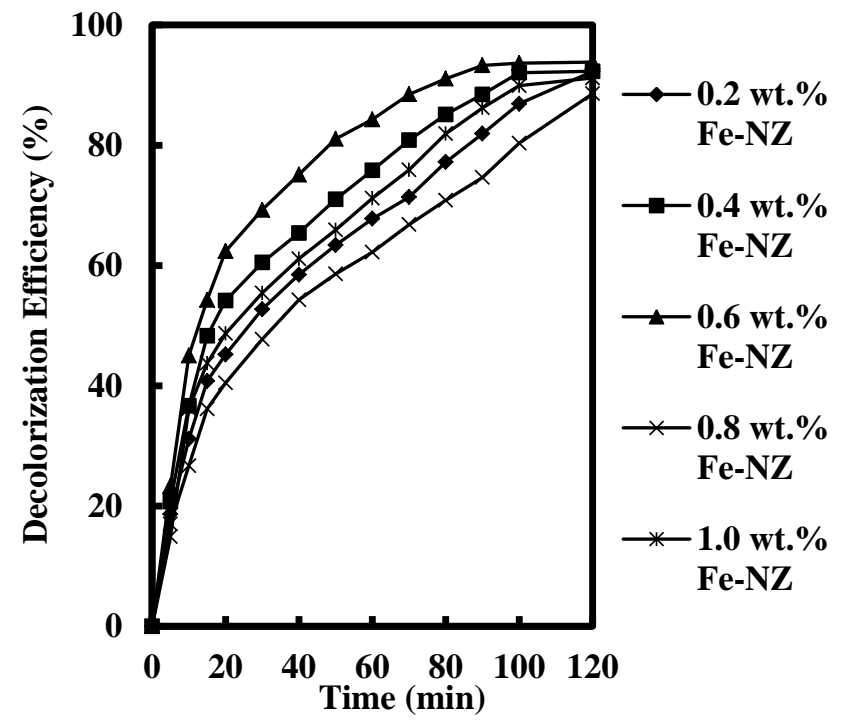

Fig. 3. Effect of iron ions loading on the decolorization of RB4. Reaction conditions: $\mathrm{pH}=2.5,\left[\mathrm{H}_{2} \mathrm{O}_{2}\right]_{\mathrm{o}}=4.0 \mathrm{mM}$, catalyst dosage $=2.0 \mathrm{~g} \mathrm{~L}^{-1},[\mathrm{RB}]_{\mathrm{o}}$ $=50 \mathrm{mg} \mathrm{L}^{-1}$, temperature $=30^{\circ} \mathrm{C}$.

\section{Effect of $\mathrm{H}_{2} \mathrm{O}_{2}$ Concentration}

In heterogeneous Fenton-like reaction, $\mathrm{H}_{2} \mathrm{O}_{2}$ become the source of $\bullet \mathrm{OH}$ radical (Eq. (7) to Eq. (9)). The generated $\bullet \mathrm{OH}$ 
radical able to degrade and oxidize many organic pollutants (Eq. 10). The influence of $\mathrm{H}_{2} \mathrm{O}_{2}(4-24 \mathrm{mM})$ is presented in Fig. 4.

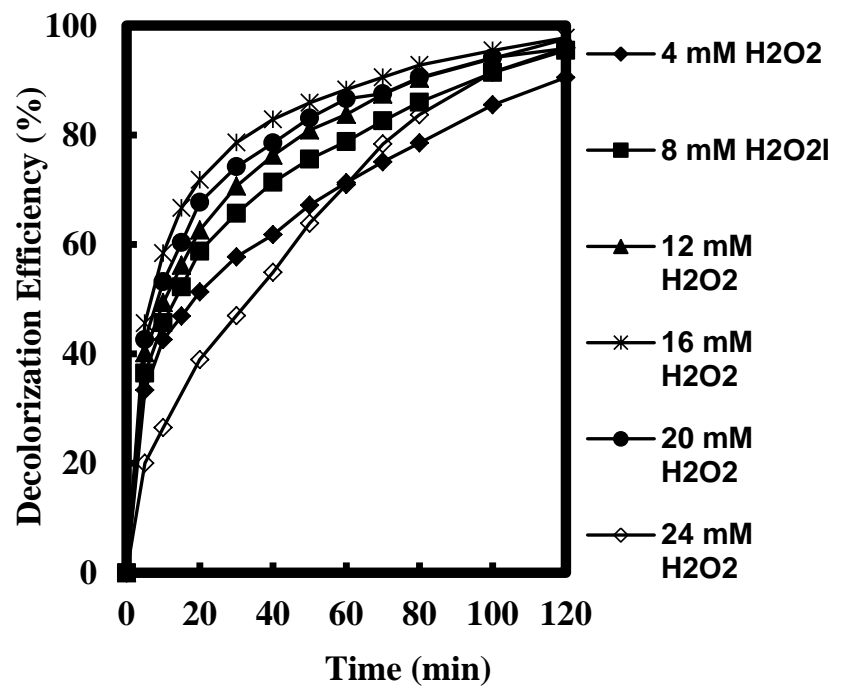

Fig. 4. Effect of $\mathrm{H}_{2} \mathrm{O}_{2}$ on the decolorization of RB4. Reaction conditions: $0.60 \mathrm{wt} \%$ of Fe-NZ, $[\mathrm{RB}]_{\mathrm{o}}=50 \mathrm{mg} \mathrm{L}^{-1}, \mathrm{pH}=2.5$, catalyst dosage $=3 \mathrm{~g} / \mathrm{L}$, temperature $=30^{\circ} \mathrm{C}$

It can be seen that the decolorization efficiency was increased from $90.53 \%$ to $97.80 \%$ as the $\mathrm{H}_{2} \mathrm{O}_{2}$ increased from $4 \mathrm{mM}$ to $16 \mathrm{mM}$ due to enhanced generation of reactive - OH. However, the decolorization efficiency decreased with further increased in $\mathrm{H}_{2} \mathrm{O}_{2}$ dosage due to scavenging of ${ }^{\circ} \mathrm{OH}$ with itself or by the superfluous of $\mathrm{H}_{2} \mathrm{O}_{2}$ (Eq. (7) and (8). The superfluous amount of $\mathrm{H}_{2} \mathrm{O}_{2}$ would react with ${ }^{\circ} \mathrm{OH}$ to produce hydroperoxyl radical $\left(\mathrm{HO}_{2}{ }^{\circ}\right)$ which is less reactive (Eq. (7)) [26]. The hydroperoxyl radical is less reactive and did not contribute to degradation of RB4 which lead to decrease in decolorization efficiency (Eq. (9)).

$$
\begin{gathered}
\mathrm{H}_{2} \mathrm{O}_{2}+\mathrm{OH}^{\cdot} \rightarrow \mathrm{HO}_{2}^{\cdot}+\mathrm{H}_{2} \mathrm{O} \\
\mathrm{OH}^{\cdot}+\mathrm{OH}^{\cdot} \rightarrow \mathrm{H}_{2} \mathrm{O} \\
\mathrm{HO}_{2}+\mathrm{OH}^{\cdot} \rightarrow \mathrm{H}_{2} \mathrm{O}+\mathrm{O}_{2}
\end{gathered}
$$

\section{E. Effect of Initial $p H$ Value}

Fig. 4 shows the performance of Fe-NZ at different $\mathrm{pH}$ values (2-5). Increasing $\mathrm{pH}$ value from $2-3$ favoured the decolorization of $\mathrm{RB} 4$ while the higher $\mathrm{pH}$ value $(\mathrm{pH}>3)$ decreased the catalytic activity. The maximum decolorization efficiency of RB4 was achieved at pH 2.5 with $98 \%$ decolorization efficiency due to enhance formation of highly reactive $\mathrm{OH}^{\circ}$ radical at an acidic condition due to the presence of photons [27]. Similar results were also reported by other researchers in heterogeneous Fenton-like reaction [12], [13]. Several researchers reported that the $\mathrm{pH}$ value around $2.5-$ 3.0 are the common optimal value for Fenton and Fenton-like reactions [12], [28]. At high $\mathrm{pH}$ value $(\mathrm{pH}>3)$ the decolorization was lower due to the iron sludge formation. At the neutral $\mathrm{pH}$, iron ferrous precipitate is in the form of iron sludge. In addition, the stability of $\mathrm{H}_{2} \mathrm{O}_{2}$ which decomposed to water and oxygen (Eq. (11)), the scavenging effect of $\mathrm{OH}^{\circ}$ by $\mathrm{H}+$ (Eq. (10)) and the lower oxidation ability of $\mathrm{OH}^{*}$ at high $\mathrm{pH}$ value also contribute to the low decolorization efficiency of RB 4 [29].

$$
\begin{gathered}
\mathrm{OH}^{\bullet}+\mathrm{H}^{+}+\mathrm{e}^{-} \rightarrow \mathrm{H}_{2} \mathrm{O} \\
\mathrm{H}_{2} \mathrm{O}_{2} \rightarrow \mathrm{H}_{2} \mathrm{O}+\mathrm{O}_{2}
\end{gathered}
$$

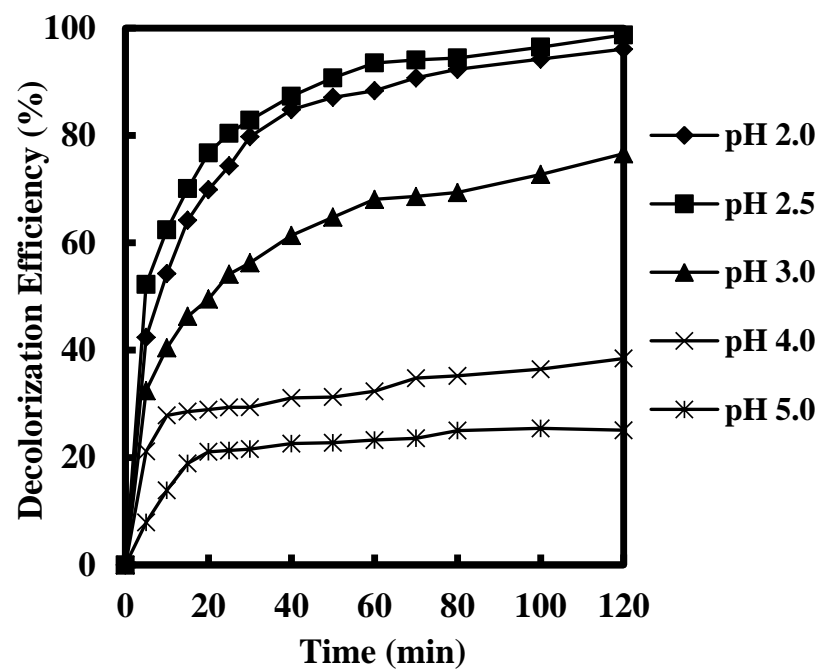

Fig. 5. Effect of $\mathrm{pH}$ on the decolorization of RB4. Fig. 4: Reaction conditions: $0.60 \mathrm{wt} \%$ of Fe-NZ, $[\mathrm{RB}]_{\mathrm{o}}=50 \mathrm{mg} \mathrm{L}^{-1},\left[\mathrm{H}_{2} \mathrm{O}_{2}\right]_{\mathrm{o}}=16 \mathrm{mM}$, catalyst dosage $=$ $3 \mathrm{~g} / \mathrm{L}$, temperature $=30^{\circ} \mathrm{C}$.

\section{CONCLUSION}

Fe-natural zeolite showed promising catalytic activity for effective decolorization of Reactive Blue 4 in heterogeneous Fenton-like reaction. Heterogeneous Fenton reaction play a prominent role in decolorization of RB4 where the iron species available on the surface of the catalyst or in the interlayer of catalyst could react with $\mathrm{H}_{2} \mathrm{O}_{2}$ to generate the highly reactive $\cdot \mathrm{OH}$ for decolorization of $\mathrm{RB} 4$ dye. The maximum decolorization of $98.71 \%$ was achieved in 120 min under the following condition: $0.60 \mathrm{wt} \%$ of iron ions loading on natural zeolite, $\mathrm{H}_{2} \mathrm{O}_{2}$ concentration of $16 \mathrm{mM}$ and initial $\mathrm{pH}$ of 2.5. The use of natural zeolite as support for Fenton-like process could be a practical and economical substitute for synthetic zeolite as it is abundant, low-cost and exhibited higher decolorization efficiency.

\section{CONFLICT OF INTEREST}

The authors declare no conflict of interest.

\section{AUTHOR CONTRIBUTIONS}

Hamizura Hassan was involved in experimental works and analysis, compilation results and drafting the manuscript whereas Bassim H. Hameed supervised the project, verifying the result for its intellectual content as well as provided critical feedback. All authors had approved the final version.

\section{ACKNOWLEDGMENT}

The authors would like to thank Institute of Leadership and Development (ILD) Universiti Teknologi MARA, Cawangan Pulau Pinang for the financial support in publishing this paper. 


\section{REFERENCES}

[1] H. T. Van, L. H. Nguyen, T. K. Hoang, T. P. Tran, A. T. Vo, T. T. Pham, and X. C. Nguyen, "Using FeO-constituted iron slag wastes as heterogeneous catalyst for Fenton and ozonation processes to degrade Reactive Red 24 from aqueous solution," Separation Purification Technology, vol. 224, pp. 431-42, October 2019.

[2] Z. Oruç, M. Ergüt, D. Uzuno, and A. Özer, "Green synthesis of biomass-derived activated carbon / Fe- $\mathrm{Zn}$ bimetallic nanoparticles from lemon (Citrus limon (L.) Burm.f.) wastes for heterogeneous Fenton-like decolorization of Reactive Red 2," Journal of Environmental Chemical Engineering, vol. 7, pp. 103231, August 2019.

[3] L. Singh, P. Rekha, and S. Chand, "Cu-impregnated zeolite Y as highly active and stable heterogeneous Fenton-like catalyst for degradation of Congo red dye," Separation Purification Technology, vol. 170, pp. 321-336, June 2016.

[4] E. Guivarch, S. Trevin, and C. Lahitte, "Degradation of azo dyes in water by Electro-Fenton process," Environmental Chemistry Letters, vol. 1, pp. 38-44, March 2003.

[5] Y. Ahmed, Z. Yaakob, and P. Akhtar, "Degradation and mineralization of methylene blue using a heterogeneous photo-Fenton catalyst under visible and solar light irradiation," Catalysis Science and Technology, vol. 6, pp. 1222-1232, November 2015.

[6] H. Hassan and B. H. Hameed, "Oxidative decolorization of Acid Red 1 solutions by Fe-zeolite Y type catalyst," Desalination, vol. 276, pp. 45-52, April 2011.

[7] A. Garc1, "Study of kinetic parameters related to the decolourization and mineralization of reactive dyes from textile dyeing using Fenton and photo-Fenton processes," Dye Pigment, vol. 75, pp. 647-652, 2007.

[8] S. Adityosulindro C. Julcour, and L. Barthe, "Heterogeneous Fenton oxidation using Fe-ZSM5 catalyst for removal of ibuprofen in wastewater," Journal of Environmental Chemical Engineering, vol. 6 , pp. 5920-5928, September 2008.

[9] R. Bulánek, R. Hrdina, and A. F. Hassan. "Preparation of polyvinylpyrrolidone modified nanomagnetite for degradation of nicotine by heterogeneous Fenton process," Journal of Environmental Chemical Engineering, vol. 7, p. 102988, February 2019.

[10] J. Laat and H. Gallard, "Catalytic decomposition of hydrogen peroxide by $\mathrm{Fe}(\mathrm{III})$ in homogeneous aqueous solution: Mechanism and kinetic modeling," Environmental Science and Technology, vol. 33, pp. 27262732, 1999.

[11] L. Lyu, L. Zhang, Q. Wang, Y. Nie, and C. Hu, "Enhanced fenton catalytic efficiency of $\gamma-\mathrm{Cu}-\mathrm{A} 12 \mathrm{O} 3$ by $\sigma-\mathrm{Cu}^{2+}-$ ligand complexes from aromatic pollutant degradation," Environmental Science and Technology, vol. 49, pp. 8639-8647, June 2015.

[12] M. Rostamizadeh, A. Jafarizad, and S. Gharibian, "High efficient decolorization of Reactive Red 120 azo dye over reusable Fe- ZSM-5 nanocatalyst in electro-Fenton reaction", Separation Purification Technology, vol. 192, pp 340-347, August 2017.

[13] H. Hassan and B. H. Hameed, "Fenton-like oxidation of acid red 1 solutions using heterogeneous catalyst based on ball clay," International Journal Environmental Science and Development, vol. 2, pp. 218-222, June 2011.

[14] Y. Yao et al., "Efficient removal of dyes using heterogeneous Fenton catalysts based on activated carbon fibers with enhanced activity," Chemical Engineering Science, vol. 101, pp. 424-431, June 2013.

[15] M. Aleksić, H. Kušić, N. Koprivanac, D. Leszczynska, and A. L. Božić, "Heterogeneous Fenton type processes for the degradation of organic dye pollutant in water - The application of zeolite assisted AOPs," Desalination, vol. 257, pp. 22-29, April 2010.

[16] S. Shin, H. Yoon, and J. Jang, "Polymer-encapsulated iron oxide nanoparticles as highly efficient Fenton catalysts," Catalysis Communication, vol. 10, pp. 178-182, September 2008.

[17] X. Zhong, S. Royer, H. Zhang, Q. Huang, L. Xiang, S. Valange, and J. Barrault, 'Mesoporous silica iron-doped as stable and efficient heterogeneous catalyst for the degradation of C. I. Acid Orange 7 using sono - photo-Fenton process," Separation Purification Technology, vol. 80, pp. 163-171, May 2011.

[18] M. E. M. Ali et al., "Heterogeneous Fenton process using steel industry wastes for methyl orange degradation," Applied Water Science, vol. 3, pp. 263-270, January 2013.

[19] S. Wang and Z. H. Zhu, "Characterisation and environmental application of an Australian natural zeolite for basic dye removal from aqueous solution," Journal of Hazardous Material, vol. 136, pp. 946 952, February 2006.

[20] E. Erdem, N. Karapinar, and R. Donat, "The removal of heavy metal cations by natural zeolites," Journal of Colloid and Interface Science, vol. 280, pp. 309-314, December 2004.
[21] T. To, N. Phan, A. N. Nikoloski, P. A. Bahri, and D. Li, "Enhanced removal of organic using $\mathrm{LaFeO} 3$-integrated modified natural zeolites via heterogeneous visible light photo-Fenton degradation," Journal of Environmental Management, vol. 233, pp. 471-480, 2019.

[22] O. B. Ayodele and B. H. Hameed, "Development of kaolinite supported ferric oxalate heterogeneous catalyst for degradation of 4-nitrophenol in photo-Fenton process", Applied Clay Science, vol. 84, pp. 171-181, October 2013.

[23] M. Noorjahan, V. D. Kumari, M. Subrahmanyam, and L. Panda, "Immobilized Fe(III)-HY: An efficient and stable photo-Fenton catalyst," Applied Catalysis B: Environmental, vol. 57, pp. 291-298, January 2005.

[24] M. Luo, D. Bowden, and P. Brimblecombe, "Catalytic property of $\mathrm{Fe}-\mathrm{Al}$ pillared clay for Fenton oxidation of phenol by $\mathrm{H}_{2} \mathrm{O}_{2}$, , Applied Catalysis B: Environmental, vol. 85, pp. 201-206, 2009.

[25] J. M. Monteagudo, A. Durán, I. S. Martin, and A. Carnicer, "Roles of different intermediate active species in the mineralization reactions of phenolic pollutants under a UV-A/C photo-Fenton process," Applied Catalysis B: Environmental, vol. 106, pp. 242-249, May 2011.

[26] M. Neamtu, A. Yediler, I. Siminiceanu, and A. Kettrup, "Oxidation of commercial reactive azo dye aqueous solutions by the photo-Fenton and Fenton-like processes," Journal of Photochemistry and Photobiology A: Chemistry, vol. 161, pp. 87-93, May 2003.

[27] K. M. Valkaj et al., "Phenol oxidation with hydrogen peroxide using Cu/ZSM5 and Cu/Y5 catalysts," Polish Journal of Chemical Technology, vol. 13, pp. 28-36, 2011.

[28] J. Shen, Y. Li, Y. Zhu, Y. Hu, and C. Li, "Aerosol synthesis of Graphene-Fe3O4 hollow hybrid microspheres for heterogeneous Fenton and electro-Fenton reaction," Journal of Environmental Chemical Engineering, vol. 4, pp. 2469-2476, April, 2016.

[29] H. S. El-desoky, M. M. Ghoneim, R. El-sheikh, and N. M Zidan, "Oxidation of Levafix CA reactive azo-dyes in industrial wastewater of textile dyeing by electro-generated Fenton's reagent," Journal of Hazardous Materials, vol. 175, pp. 858-865, 2010.

Copyright (C) 2020 by the authors. This is an open access article distributed under the Creative Commons Attribution License which permits unrestricted use, distribution, and reproduction in any medium, provided the original work is properly cited (CC BY 4.0).

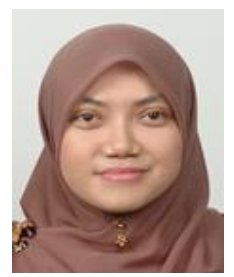

Hamizura Hassan received her Ph.D in chemical engineering, from Universiti Sains Malaysia, Malaysia in 2019. She is now senior lecturer at Faculty of Chemical Engineering, Universiti Teknologi MARA, Cawangan Pulau Pinang. Her research interest is catalysis, biofuels, and wastewater treatment. She has published an article in Energy, Bioresource Technology, Chemical Engineering and Desalination Journal. According to Google Scholar, Hamizura Hassan's publications have been cited more than 400 times. She has an author of h-index of 5 and her i-10 index is 5 .

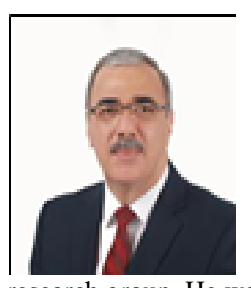

Bassim H. Hameed received his Ph.D. in chemical engineering from the University of Salford, United Kingdom in 1992. He is a professor at the Department of Chemical Engineering, Qatar University. Previously, he was a professor at the School of Chemical Engineering, Universiti Sains Malaysia (USM) for the past 20 years where he lead the Reaction Engineering \& Adsorption (READ) research group. He was appointed as a guest professor at the Yunnan Minzu University, China from 2014-2017 and a visiting professor at the Universiti Teknologi Petronas (UTP), Malaysia from April 2017 to April 2019. His research interest is Reaction Engineering and Adsorption Technology, with applications in energy and the environment. Professor Bassim was included by Clarivate Analytics in its prestigious list of Highly Cited Researchers in Engineering for five consecutive years (2014-2018). Professor Bassim was listed as one of the Most Cited Researchers for Chemical Engineering, and Environmental Science and Engineering Subjects of 2016 by the Shanghai Global Rankings of Academic Subjects. He also received the Ministry of Higher Education's Malaysia's Rising Star Award in 2016 and Malaysia's Research Star Award in 2017. He has successfully supervised the works of 5 postdoctoral fellows, $21 \mathrm{Ph} . \mathrm{D}$. and $26 \mathrm{MSc}$ students, and more than 70 final-year research projects to completion. He has achieved a milestone of 21 research grants as a principal investigator. To date, he has published more than 280 articles in ISI-indexed journals. He has also published 100 articles in other international and national journals and proceedings. According to Google Scholar, Professor Bassim's publications have been cited more than 34,600 times. He has an author h-index of 94 and his i-10 index is 263. 